\title{
Drinking water issues and concerns of urban residents of the Pacific Northwest, USA
}

\author{
R. Mahler ${ }^{1}$, M. Barber ${ }^{2}$ \& B. Shafii ${ }^{3}$ \\ ${ }^{I}$ Soil and Environmental Sciences, University of Idaho, USA \\ ${ }^{2}$ Department of Civil Engineering, University of Utah, USA \\ ${ }^{3}$ Department of Plant, Soils and Entomological Sciences, \\ University of Idaho, USA
}

\begin{abstract}
Urban residents of the Pacific Northwest region of the USA consider drinking water their most important water resource issue. We developed a survey instrument to measure urban satisfaction with drinking water supplies. Data were collected using mail-based surveys conducted at five-year intervals in 2002, 2007 and 2012. Each survey contained 11 questions about drinking water and was mailed to 2,200 randomly chosen residents of Alaska, Idaho, Oregon and Washington. Return rates in excess of $50 \%$ were received for each survey ensuring that the results are statistically valid. The 2002 survey results were used as base line data. Based on the 2012 survey results, $86.2 \%$ of the urban residents consider their drinking water safe. Despite the high level of satisfaction with the drinking water resource $17.5,26.5$ and $34.6 \%$ of the survey respondents use water softeners, bottled water and water filters as an add on to their municipally supplied drinking water, respectively. Conversely, satisfaction with drinking water has decreased over the last 10 years $(91 \%$ in 2002 vs. $86 \%$ in 2012). The use of in-house water filters has also significantly increased with time $(25 \%$ in 2002 vs. $35 \%$ in 2012). Overall, the urban public is satisfied that their home drinking water is safe; however, in the last 10 years there has been a trend toward more skepticism and additional in-home treatment of drinking water.

Keywords: public opinion, drinking water issues, drinking water safety, adult education, public outreach, bottled water, home water treatment.
\end{abstract}




\section{Introduction}

Drinking water has been protected and treated to some extent by societies for over 3,000 years. The ancient Mesopotamians were the first to link certain human activities with water that was unsafe for drinking. Later the Romans learned how to seek the best water sources, transport it to reservoirs, use sand filters to make it purer and then pipe it to fountains in cities where it could be conveniently accessed by the masses. Since the 1880 s, many cities in Europe and North America have taken on the responsibility of providing safe drinking water for citizens first by filtration and then by chlorination to remove microbial pathogens. By the 1950s, guidelines for inorganic chemicals including nitrate-N and lead were developed. The explosion in the development and use of organic chemicals by industry and agriculture led to increased scrutiny and the development of standards by the 1970s. To further protect Americans Congress passed the Safe Drinking Water Act of 1974. Consequently, both human-made and natural radionuclides were evaluated and drinking water standards were developed. Finally, the clarity (turbidity) of surface waters used as drinking water was regulated.

Consumer satisfaction with drinking water has been measured in several studies [1-4]. However, many factors have been found to be involved in the public perception of drinking water quality $[5,6]$. Important factors involved in overall public perception include: flavor, risk perception, attitudes toward chemicals often found in drinking water, trust in the public water supply system, past problems attributed to water quality and information provided by the local media [5-10]. Although all of the listed factors are important the credibility of societal institutions providing the drinking water and the regulatory agency providing standards and enforcement for pathogens, inorganic chemicals, organic chemicals, radionuclides and turbidity are probably most important [11]. In recent years USA consumers have been able to purchase different quantities of bottled water whose quality is regulated by the United States Food and Drug Administration (USFDA). Over $20 \%$ of consumers have opted for bottled water as an alternative to tap water, which is regulated by the United States Environmental Protection Agency (USEPA) [11, 12].

Since 1987 in the USA an increased emphasis has been placed on public education as a mechanism to improve the nation's water resources through knowledge and voluntary actions. This idea has been implemented using a regional rather than a state-by-state approach. To accurately determine the effectiveness of regional programming, it is important both to establish base-line information about public perceptions and literacy, and then to measure change in public attitudes and actions over time. Furthermore, to identify the best opportunities for successful regional programming, it is imperative to understand the similarities and differences that exist among the target audiences. In the fourstate (Alaska, Idaho, Oregon, Washington) Pacific Northwest Region, a survey instrument was developed to provide base-line information on public attitudes regarding water resources in 2002 from which future Extension programming outcomes can be measured $[14,15]$. This initial regional survey documented 
public attitudes about water resources in 2002. At that time it was anticipated that follow-up water resource surveys would be conducted at 5- (2007), 10(2012), 15- (2017), 20- (2022) and 25- (2027) year intervals. This paper evaluates information about public perceptions, attitudes and consumption of drinking water provided by public water systems in urban areas of the Pacific Northwest. This paper evaluates how the urban public views the quality of water delivered to the consumer by public municipalities.

\section{Methodology}

A survey instrument was developed to access public priorities, attitudes and concerns about water resource issues in the Pacific Northwest. The survey was administered to the general public in 2002, 2007 and 2012 to evaluate changes over time. The specific survey questions covered in this paper deal with responses to questions about drinking water. The public was asked the following drinking water related questions: (1) How important is clean drinking water to you? (2) Where do you primarily get your drinking water? (3) Do you feel that your home drinking water is safe to drink? and (4) Do you have your home drinking water tested? In addition to those four specific questions information was also collected about the following: (1) water softeners, (2) in-home water filters, (3) use of bottled water, (4) satisfaction with tap water, and (5) water system connections. The survey target audience was a representative sample of the 9,000,000 adult residents of the four Pacific Northwest states (Alaska, Idaho, Oregon, Washington). Drinking water questions were asked both urban and rural residents so that answers could be compared between these two demographic groups.

In addition, demographic information, including state of residence, community size, length of time residing in the region, gender, age, and educational level were also collected from survey respondents.

In 2012, a target of 950 completed questionnaires was chosen as the survey goal to result in a sampling error of 4 to $6 \%$ [16]. The survey process was designed to receive a completed survey return rate in excess of $50 \%$. Addresses were obtained from a professional social sciences survey company (SSI, Norwich, CT). Four mailings were planned to achieve the $50 \%$ return rate [17]. The mailing strategy used was identical to that of the 2002 and 2007 samplings [18].

Surveys were actually sent to 2,126 residents; however, because address changes, deaths of people on the mailing list and delivery problems, the actual sample population was 1,886 . The survey process was designed to receive a completed survey return rate in excess of 50\%. If more than 943 surveys were returned completed, then sampling error could be assumed to be less than $5 \%$ $[16,17]$.

It only took three mailings were to achieve this target return rate of $50 \%$. The first mailing, which took place in May 2012, included the water issues survey form, a business reply envelope, and a cover letter that: (1) identified the survey's authors; (2) explained the purpose of the survey; (3) assured the 
respondent of anonymity; and (4) asked the respondents to fill out and return the survey via the business reply envelope. The second mailing occurred 5 weeks later (June 2012) and consisted of a postcard that stressed the importance of the survey and remind the respondent to fill out and return the survey sent out in the first mailing. Five weeks later (August 2012), the third mailing was sent to residents who did not respond to the first or second mailing. This mailing included a reminder letter, another copy of the water issues survey, and a business reply envelope.

Survey answers were coded and entered into Microsoft Excel. Missing data were excluded from the analysis. The data were analyzed at two levels using SAS [19]. The first level of analysis generated frequencies, while the second level evaluated the impacts of demographic factors. Significance $(\mathrm{P}<0.05)$ to demographic factors was tested using a chi-square distribution [20].

\section{Results and discussion}

The survey methodology used in the study was not designed to be unique, but rather to be used as a tool to ascertain useful information. The survey methodology is designed point out the strengths and weaknesses of drinking water delivered by municipalities to urban consumers in the Pacific Northwest. Appropriate education programs will be developed for Pacific Northwest audiences based on this information.

The 2012 Pacific Northwest Water Issues Survey achieved a return rate of $54.1 \%$ (1,021 either fully or partially completed and returned out of 1,886). Fifty-five percent of the survey respondents were male. Over $38 \%$ of survey respondents lived in communities of more than 100,000 people. Conversely, $16 \%$ of respondents lived in towns with less than 7,000 people. Thirty-nine percent of respondents had lived in the Pacific Northwest all of their lives. Ninety percent of survey respondents were high school graduates. Overall, the demographics of the survey respondents (except for gender) closely reflected the actual demographics of the region. Consequently, when coupled with the low sampling error of the survey, respondents are often equated to residents in the following discussion.

\subsection{Source of drinking water}

Since 2002, surveys have shown that $99 \%$ of urban residents of the Pacific Northwest consider safe drinking water to be a very or extremely important issue. In fact these residents rank safe drinking water as the most important environmental issue affecting them.

On a regional basis, $68.8 \%$ of Pacific Northwest residents relied on public water supply systems for their drinking water in 2012 (Table 1). This number increased to $86 \%$ when only urban residents are counted. When the purchasing bottled water and the "I don't know" responses are eliminated virtually $94 \%$ of urban residents depended on municipal public water supply systems. This 
number is statistically similar to survey values obtained in the 2002 and 2007 regional surveys.

As expected, town size affected the source of drinking water supply (Table 2); however, both respondent age and education level also interacted with water source. In the case of water source both education level and age probably affected how much people knew about their water source, rather than the source itself.

Table 1: $\quad$ Primary source of drinking water for residents of the Pacific Northwest based on the 2012 PNW survey.

\begin{tabular}{lc}
\hline \multicolumn{1}{c}{ Drinking water source } & Percent citing \\
\hline Private supply & 22.9 \\
Public supply - municipal & 57.4 \\
Public supply - rural water district & 11.4 \\
Purchase bottled water & 5.4 \\
Don't know & 3.0 \\
\hline
\end{tabular}

Table 2: $\quad$ Significance of interactions (NS; $\left.0.05^{*} ; 0.01 * *\right)$ for the questions about drinking water and the demographic factors of where people live (WL), town size (TS), length of time in the Pacific Northwest (PNW), gender (GDR), age (AGE) and formal education (ED) based on responses to the 2012 PNW survey.

\begin{tabular}{lcccccc}
\hline \multicolumn{1}{c}{ Question } & \multicolumn{5}{c}{ Significance of interaction } & \multirow{2}{*}{} \\
\cline { 3 - 6 } & WL & TS & PNW & GDR & AGE & ED \\
\hline DW source & $0.01^{* *}$ & $0.01^{* *}$ & NS & NS & $0.01^{* *}$ & $0.01^{* *}$ \\
Water softener & $0.02^{*}$ & NS & NS & NS & NS & NS \\
Water filter & NS & NS & NS & NS & $0.01^{* *}$ & NS \\
Five gallon purchases & NS & NS & NS & NS & $0.01^{* *}$ & NS \\
Use bottled water & NS & NS & $0.04^{*}$ & NS & $0.01^{* *}$ & $0.01^{* *}$ \\
Never use bottled water & NS & NS & NS & NS & $0.00^{* *}$ & NS \\
Satisfied with DW & NS & NS & NS & NS & NS & $0.01^{* *}$ \\
Not satisfied with DW & NS & NS & NS & $0.01^{* *}$ & NS & NS \\
Separate water systems & NS & $0.04^{*}$ & NS & NS & NS & NS \\
DW safe to drink & NS & NS & NS & $0.01^{* *}$ & $0.01^{* *}$ & $0.01^{* *}$ \\
Is DW tested? & $0.01^{* *}$ & $0.01^{* *}$ & NS & NS & NS & NS \\
\hline
\end{tabular}

In addition to the source of drinking water survey respondents were asked to indicate (by checking) the following items that applied to drinking water in their home: I have a water softener (Water softener); I have a water filter (Water filter); I purchase 5 gallon containers of drinking water (Five gallon purchases; I often use bottled water for drinking purposes (Use bottled water); I never buy bottled water (Never use bottled water); I am satisfied with my drinking water piped into house (Satisfied with DW); I am not satisfied with my drinking water - piped into house (Not satisfied with DW); and My drinking water is separate from my water supply system (Separate water system). 
Significant interactions for each survey drinking water question between where respondents lived (WL), town size (TS), length of time living in the Pacific Northwest (PNW), gender (GDR), age (AGE), and formal education level (ED) are shown in Table 2. Age and formal education level were the demographic factors that most often affected responses to drinking water questions.

\subsection{Safe drinking water}

The vast majority of survey respondents $(86.2 \%)$ felt that water they obtained from the tap in their home was safe to drink. There were however, interactions with gender, age and education level of the respondents. Males were more likely to consider their home tap water safe to drink than females (92.4 vs. 81.2\%).

Age also had a significant impact on the response to the safety of drinking water at the tap (Table 3 ). In general respondents less than 40 years old were less likely to consider their home tap water safe to drink than older respondents. Although a statistical difference existed between the less than 40 and more than 40 age groups it should be pointed out that the vast majority of urban survey respondents considered their tap water safe.

Formal education level of the survey respondents also affected the response to the safety of home drinking water at the tap (Table 4). Here, the older the survey respondent, the more likely water at the tap was considered safe to drink. Again, even though there was a statistical difference due to education level the overwhelming majority of urban residents considered water at the tap safe to drink.

Table 3: Interaction between saying tap water is safe to drink and respondent age based on the 2012 PNW survey.

\begin{tabular}{lc}
\hline \multicolumn{1}{c}{ Respondent age } & Percent citing \\
\hline Less than 30 & 79.1 \\
30 to 39 & 80.4 \\
40 to 49 & 85.6 \\
50 to 59 & 88.6 \\
60 to 69 & 87.8 \\
More than 70 & 87.0 \\
\hline
\end{tabular}

Table 4: Interaction between saying that tap water is safe to drink and formal educational level of respondents based on the 2012 PNW survey.

\begin{tabular}{lc}
\hline \multicolumn{1}{c}{ Respondent education level } & Percent citing \\
\hline Less than high school diploma & 79.1 \\
High school diploma & 80.1 \\
Some college & 84.8 \\
College graduate & 89.5 \\
Advanced college degree & 90.6 \\
\hline
\end{tabular}


In many situations water safety and water satisfaction are not necessarily the same. Here in the Pacific Northwest well over two-thirds of urban survey respondents were satisfied with their drinking water. An interaction between drinking water satisfaction and respondent age was observed. Respondents without a high school diploma were less likely to be satisfied with their drinking water (Table 5). Even though this statistical difference was observed the main point of the survey data is that there is widespread satisfaction with drinking water in urban areas of the Pacific Northwest.

Table 5: Interaction between likelihood of being satisfied with their drinking water and formal educational level of respondents based on the 2012 PNW survey.

\begin{tabular}{lc}
\hline \multicolumn{1}{c}{ Respondent education level } & Percent citing \\
\hline Less than high school diploma & 55.6 \\
High school diploma & 71.9 \\
Some college & 65.0 \\
College graduate & 73.4 \\
Advanced college degree & 78.3 \\
\hline
\end{tabular}

\subsection{Bottled water}

Approximately $27 \%$ of survey respondents reported that they often use bottled water. Very little of this water is consumed in the home; however, many respondents often travel or recreate with bottled water. Consequently, they use bottled water more as a convenience rather than for health-related issues.

Interactions were observed between bottled water use and the demographic factors of age and education level. Survey respondents less than 30 years old and between the ages of 40 and 49 were more likely to use bottled water than other age groups (Table 6). If the age group data were combined into two groups those respondents younger than 50 and 50 or older, the less than 50 age group was almost twice as likely to often use bottled water. This can be explained by the observation that many older Pacific Northwest urban residents grew up

Table 6: Interaction between often using bottled water and respondent age based on the 2012 PNW survey.

\begin{tabular}{lc}
\hline \multicolumn{1}{c}{ Respondent age } & Percent citing \\
\hline Less than 30 & 38.3 \\
30 to 39 & 25.6 \\
40 to 49 & 43.5 \\
50 to 59 & 19.2 \\
60 to 69 & 26.4 \\
More than 70 & 20.7 \\
\hline
\end{tabular}


without much exposure to bottled water and were thus more likely to always use tap water. Basically they did not have a compelling reason to seek an alternative source of drinking water.

Formal education level also impacted the use of bottled water by urban consumers in the Pacific Northwest. College graduates with four-year and advanced degrees were less likely to use bottled water than consumers with some college, a high school diploma or less than a high school diploma (Table 7). This difference due to formal education level is likely due to the more educated consumers knowing that because of strong federal regulations (Safe Drinking Water Act of 1974) their tap water is at least as safe as bottled water.

Table 7: Interaction between likelihood of often using bottled water being and formal educational level of respondents based on the 2012 PNW survey.

\begin{tabular}{lc}
\hline \multicolumn{1}{c}{ Respondent education level } & Percent citing \\
\hline Less than high school diploma & 29.6 \\
High school diploma & 29.7 \\
Some college & 32.9 \\
College graduate & 23.4 \\
Advanced college degree & 17.2 \\
\hline
\end{tabular}

\subsection{In home water filters}

Over $34 \%$ of urban residents have installed a secondary water filter in their home. Most of these filters are either located on the kitchen sink faucet or the filter is in a small stand- alone device coupled with a water pitcher. The standalone pitcher device can be placed in the refrigerator to supply drinking water at the consumer's convenience. Consumers use filters because they believe that these devices improve the taste of municipally supplied drinking water.

The demographic factor of respondent age affected the use of in-home water filters in urban areas of the Pacific Northwest. This age effect was striking as the use of an in-home water filter decreased with increasing age (Table 8). Residents

Table 8: Interaction between having a water filter in the house/kitchen and respondent age based on the 2012 PNW survey.

\begin{tabular}{lc}
\hline \multicolumn{1}{c}{ Respondent age } & Percent citing \\
\hline Less than 30 & 44.7 \\
30 to 39 & 44.1 \\
40 to 49 & 42.6 \\
50 to 59 & 40.9 \\
60 to 69 & 31.3 \\
More than 70 & 24.6 \\
\hline
\end{tabular}


in the $60+$ age groups were less likely to have a filter - probably because they were satisfied with the tap water they were raised with and had no real reason to seek additional treatment.

Although not a water filter, another $17.5 \%$ of urban residents had water softeners to reduce levels of calcium, magnesium and/or iron in their home water supply. This treatment of hard water would improve the bathing and laundry aspects of their water supply.

\subsection{Water testing}

Only $26.5 \%$ of residents have their water tested on a regular basis. Community size and where a person lived impacted a respondent's answer to this question. Residents of towns with more than 25,000 people were less likely to have their water tested than people from smaller communities (Table 9). Basically, city residents expect that their public water system will do all the testing required to ensure that their drinking water is safe. Conversely, people in the rural areas understand that in many situations the individual is responsible for water safety. Consequently, they are more likely to have their water tested. Home drinking water was tested by $17.9,38.0$ and $49.0 \%$ of survey respondents living in city limits, outside of city limits (non-farm), and on-farms, respectively.

Table 9: Interaction between likelihood of having home water tested and community size based on the 2012 PNW survey.

\begin{tabular}{lc}
\hline Community size & Percent citing \\
\hline More than 100,000 & 21.6 \\
25,000 to 100,000 & 18.8 \\
7,000 to 25,000 & 29.9 \\
3,500 to 7,000 & 38.3 \\
Less than 3,500 & 38.6 \\
\hline
\end{tabular}

\section{Conclusions and recommendations}

Urban residents of the Pacific Northwest appear to be satisfied with the drinking water supplied by public water systems. The majority of residents regularly drink their home tap water. Less than $35 \%$ of residents use in-home water filters, water softeners or bottled water. Age and formal education level often affected how citizens responded to drinking water questions. Older residents seemed more satisfied with their home drinking water; however, a large majority (86\%) of all residents considered their drinking water safe.

The overall safety and satisfaction values with drinking water have declined from 91 to $86 \%$ over the past 10 years; however, few people have specific health concerns with their drinking water. From a safety standpoint public water providers and regulators have done an excellent job in the Pacific Northwest. 
There is however, room for improvement in the areas of taste and water hardness as indicated by the widespread use of in-home water filters. The use of bottled water appears to have peaked at $34.4 \%$ in 2007 and has now declined to $26.5 \%$. This drop in the use of bottled water reaffirms the confidence of the urban public in public water suppliers.

In summary the urban public has confidence that their drinking water supply in the Pacific Northwest is safe. This confidence could be increased further if public education on drinking water would become more proactive. Consequently, we propose the following three steps:

1. Provide educational opportunities so that public perceptions about drinking water quality match actual municipality monitoring data. Municipalities, state and local health organizations and university Extension should cooperate to make this effort successful.

2. Publicize the importance of the annual drinking water report (required by the SDWA) provided by local municipalities to the public.

3. Educate the public about the provisions of the Safe Drinking Water Act of 1974 (SDWA) and its major amendments in 1986 and 1996. Show how this legislation insures that publically supplied water in urban areas is safe.

\section{Acknowledgement}

The authors would like to acknowledge USDA-NIFA for supporting this survey work over the last 12 years as a portion of the Pacific Northwest Water Resources Coordination Project.

\section{References}

[1] Dunlap, Riley, E. Trends in public opinion toward environmental issues: 1965-1990. Society \& Natural Resources, 4:285-312, 1991.

[2] Falahee, M. \& MacRae, A. Consumer appraisal of drinking water: multidimensional scaling analysis. Food Quality and Preference, 6:327332, 1995.

[3] Fawell, J. K. \& Miller, D. G. Drinking water quality and the consumer. Journal of the Institution of Water and Environmental Management, 6:726-32, 1992.

[4] Syme, G. J. \& Williams, K. D. The psychology of drinking water quality: and exploratory study. Water Resources Research, 29 (12): 4003-4010, 1993.

[5] Doria, M. Factors influencing public perception of drinking water quality. Water Policy, 12: 1-19, 2010.

[6] Doria, M., Pidgeon, N. \& Hunter, P. R. Perceptions of drinking water quality and risk and its effect on behavior: a cross national study. Science of the Total Environment, 407 (21):5455-5464, 2009. 
[7] Dunlap, R. E. \& Scarce, R. Poll trends: environmental problems and protection, The Public Opinion Quarterly, 55 (4): 651-672, 1991.

[8] Mahler, R. L., Simmons, R. \& Sorensen, F. Drinking water issues in the Pacific Northwest, Journal of Extension, 43(6): 6RIB6, online at: www.joe.org/joe/2005december/rb6.shtml, 2005.

[9] Ross, V. The determinants of trust and satisfaction with drinking water quality, ARCWIS Occasional Paper, 2005.

[10] Tyler, T. R. \& Degoey, P. Trust in organizational authorities. In R.M. Kramer T.R. Tyler (Eds), Trust in Organizations, Frontiers of Theory and Research. London: Sage, 1996.

[11] Syme, G. J. \& Williams, K. D. The psychology of drinking water quality: an exploratory study. Water Resources Research, 29(12): 4003-4010, 1993.

[12] Doria, M. Bottled water versus tap water: understanding consumerspreferences, Journal of Water Health, 2006: 271-276, 2006.

[13] Hu, Z., Morton, L. W. \& Mahler, R. L. Bottled water: United States consumers and their perceptions of water quality, International Journal of Environmental Research and Public Health, 8: 565-578, 2011.

[14] Mahler, R. L., Simmons, R., Sorensen, F. \& Miner, J. R., Priority water issues in the Pacific Northwest, Journal of Extension, [On-line], 42(5). Article 5RIB3. Available at: http://www.joe.org/joe/2004october/rb3.php, 2004.

[15] Mahler, Robert L., Smolen, Michael D., Borisova, Tatiana, Boellstorff, Diane E., Adams, Damien, C. \& Sochacka, Nicola W. The national water survey needs assessment program. Natural Sciences Education, 42(1): 98103, 2013.

[16] Salent, P. \& Dillman, D., How to Conduct your own Survey. John Wiley and Sons, Inc. New York, New York, 1994.

[17] Dillman, D., Mail and Internet Surveys: The Tailored Design Method. John Wiley and Sons, Inc. New York, New York, 2000.

[18] Mahler, R. L., Gamroth, M., Pearson, P., Sorenson, F., Barber, M. E. \& Simmons, R., Information sources, learning opportunities and priority water issues in the Pacific Northwest, Journal of Extension [On-line], 48(2). Article 2RIB2. Available at: http://www.joe.org/joe/2010april/rb2.php, 2010.

[19] SAS Institute Inc., SAS Online Document 9.1.3. Cary, North Carolina: SAS Institute Inc., 2004.

[20] Babbie, E., The practice of social research. 3rd edition. Wadsworth Publishing Company, Belmont, CA. pp. 359, 424, 1983. 